\title{
LEVAR A MÚSICA ÀS CRECHES PORTUGUESAS: A IMPORTÂNCIA DE VIVÊNCIAS MUSICAIS
}

\section{TAKING MUSIC TO PORTUGUESE CRÈCHES: THE IMPORTANCE OF MUSICAL EXPERIENCES}

\author{
Ana Cecília Fernandes Pinto ${ }^{1}$ \\ CLIB - Colégio Luso-Internacional de Braga \\ ceciliapinto.1907@gmail.com \\ António José Pacheco Ribeiro ${ }^{2}$ \\ Conservatório do Vale do Sousa \\ Universidade do Minho - CIEC \\ antoniopacheco@ie.uminho.pt
}

RESUMO: O presente artigo resulta do trabalho de Estágio, realizado no contexto de Creche, integrado no plano de estudos do Mestrado em Educação Pré- Escolar e pretendeu dar a conhecer a implementação realizada durante o Projeto de Intervenção intitulado Levar a música à Creche: a importância de vivências musicais. O Projeto de Intervenção pretendeu investir na aculturação musical das crianças, através de propostas lúdicas que assumiram como principais objetivos: permitir o usufruto musical; potenciar atividades musicais diversificadas; promover o contacto com diversas formas de expressão e comunicação; promover a aprendizagem ativa através da música; e compreender o potencial da música na infância. O trabalho desenvolvido teve por base uma aposta na observação e reflexão como formas de resolver problemas e adequar práticas; a metodologia de investigação utilizada foi uma aproximação à Investigação-Ação. Os instrumentos de recolha de dados utilizados foram, para além da necessária observação, as notas de campo, o registo fotográfico e a Escala de Envolvimento da Criança: Manual - Desenvolvendo a Qualidade em Parceria (DQP). Os objetivos propostos para este trabalho foram cumpridos com sucesso, já que os momentos de intervenção se revelaram de investimento na aculturação musical do grupo, criando oportunidades para explorar e usufruir das diversas atividades, de modo a construir conhecimento de forma ativa. As crianças participaram com empenho, dedicação e mostraram-se muito interessadas pelas propostas apresentadas, revelando progressos nas

\footnotetext{
${ }^{\mathrm{I}}$ Licenciada em Educação Básica pela Universidade do Minho, Mestre em Educação Pré-Escolar também pelo Instituto de Educação da Universidade do Minho e especializada em Intervenção Psicossocial com crianças e famílias. Atualmente, desempenha funções de Educadora de Infância no CLIB - Colégio Luso-Internacional de Braga.

2 Licenciado em Ensino de Música pela Universidade de Évora e Mestre em Estudos da Criança Especialização em Educação Musical pela Universidade do Minho. Doutorou-se na Especialidade de Educação Musical, em Estudos da Criança, na Universidade do Minho. Leciona no Conservatório do Vale do Sousa, Lousada, e no Instituto de Educação da Universidade do Minho. É membro integrado do Centro de Investigação em Estudos da Criança (CIEC).
} 
suas aprendizagens, tornando-se mais autónomas e desenvolvendo o sentido de convivência em grupo. A aposta na aculturação musical das crianças desde tenra idade representa, neste sentido, um investimento na educação holística da criança e contribui em grande medida para o estabelecimento de atitudes positivas perante a música.

Palavras-chave: Música. Infância. Creche. Aculturação Musical.

ABSTRACT: This article results from the work of the Internship, carried out in the context of Kindergarten, integrated in the study plan of the Master's Degree in Pre-School Education and intended to make known the implementation carried out during the Intervention Project entitled Taking music to Kindergarten: the importance of musical experiences. The intervention project aimed to invest in the musical acculturation of children, through playful proposals that assumed as main objectives: allow musical enjoyment; enhance diverse musical activities; promote contact with various forms of expression and communication; promote active learning through music; and understand the potential of music in childhood. The work developed was based on observation and reflection as a means of solving problems and adapting practices; the research methodology used was an approach to Action Research. The data collection tools used were, in addition to the necessary observation, field notes, photographic record and the Child Involvement Scale: Handbook - Developing Quality in Partnership (DQP). The objectives proposed for this work were successfully met, since the moments of intervention proved to be an investment in the musical acculturation of the group, creating opportunities to explore and enjoy the various activities, in order to actively build knowledge. The children participated with commitment, dedication and showed great interest in the proposals presented, revealing progress in their learning, becoming more autonomous and developing a sense of group coexistence. Investing in the musical acculturation of children from an early age represents, in this sense, an investment in the holistic education of the child and contributes greatly to the establishment of positive attitudes towards music.

Keywords: Music. Childhood. Kindergarten. Musical Acculturation.

\section{INTRODUÇÃO}

A música está na nossa vida e faz parte dela nos mais variados momentos. É praticamente impossível passar um dia sem ouvir música. Para além de ser um elemento presente no nosso dia a dia desde o nascimento (ou até antes), a música representa também uma parte importante da nossa cultura. Por conseguinte, torna-se importante que todos os indivíduos sejam capazes de compreender aquilo que ouvem e a aposta nesta compreensão tem especial enfoque no período da primeira infância (GORDON, 2000a, 200ob), momento em que se deve iniciar a aculturação musical de todas as crianças, de forma lúdica e incluída na sua vida quotidiana. A falta deste investimento musical durante a infância resulta, em grande medida, na criação de estigmas e ideias, de que a aptidão musical é um dom atribuído apenas a um pequeno grupo de eleitos. Os estigmas provocam um afastamento que, por sua vez, causa dificuldades e insucesso escolar aquando do contacto formal com a música. Deste modo, como forma de evitar o insucesso, as crianças devem, desde cedo, ser incentivadas a ouvir, imitar e criar música. 
No caso específico dos contextos de educação de infância, a música é diversas vezes confinada a momentos de grande grupo onde se cantam canções que incentivam conversas relativas a temas a serem trabalhados como: as estações do ano, festividades e regras de comportamento. A música é ainda muitas vezes encarada como uma forma de acalmar as crianças ou de alternar entre momentos da rotina. Acabando por obter resultados positivos com este tipo de abordagem, os educadores de infância tendem a adotar uma visão instrumental da música na infância, assumindo este elemento tão importante da cultura de cada um como secundário, marginalizando-o em relação a outros que são, não poucas vezes, considerados mais importantes, como é o caso da linguagem verbal e da matemática. A música e o investimento na aculturação musical das crianças acaba por ser desvalorizado, na medida em que muitos educadores não lhe destinam qualquer tempo diário ou semanal que vá para além de canções sobre temas específicos ou de episódios musicais de passagem entre momentos da rotina.

Apesar de, hoje em dia, se notar um maior investimento das instituições na área, com a contratação de professores de música e a criação de atividades extracurriculares, pareceme que ainda estamos longe de uma aposta séria na aculturação musical das nossas crianças. Sobretudo porque mesmo quando existe esta aposta das instituições, as atividades musicais acabam por se realizar de forma isolada, um dia da semana e hora específica, como uma espécie de aula de Educação Musical.

Foi com uma visão de desafio e numa tentativa de alterar este paradigma, ainda que numa escala tão diminuta como um grupo de crianças, que surgiu, no âmbito do estágio curricular do Mestrado em Educação Pré-Escolar da Universidade do Minho, Portugal, o Projeto de Intervenção: Levar a música à Creche: a importância de vivências musicais. Esta ideia de levar a música à Creche, de forma lúdica e visando a aculturação musical e o desenvolvimento holístico das crianças, teve como principais objetivos: (i) permitir o usufruto da música; (ii) potenciar vivências musicais diversificadas; (iii) promover o contacto com diversas formas de expressão e comunicação; (iv) promover a aprendizagem ativa através da música; $\mathrm{e}(\mathrm{v})$ compreender o potencial da música na infância.

\section{Música e infância}

A música está, incontornavelmente, presente na vida do ser humano, desde o seu início. Os mais insignes autores da área defendem até que ainda no útero, os bebés já ouvem e respondem a estímulos sonoros, produzindo movimentos de reconhecimento de sons e canções. Moog (1976) defende que os batimentos bruscos dos bebés no útero da mãe são respostas fiéis a estímulos musicais. Também Lecanuet e Schaal (1996) e Parncutt (1993) acreditam que, nos últimos quatro meses de gestação, os fetos já respondem à estimulação sonora através dos seus movimentos. Hohmann e Weikart (1997, p. 658), autores respeitados na área da educação de infância, creem que a música se torna importante na vida da criança já que transmite emoções, "sublinha experiências e marca ocasiões pessoais e históricas".

As crianças constroem uma cultura musical autêntica, ouvindo os sons e músicas do seu meio, explorando o som de objetos e os sons que são capazes de produzir vocalmente, de modo a expressar desejos e necessidades ou apenas por pura brincadeira sonora. E esta cultura é construída não só com a família, mas também através de outras relações sociais, dando especial enfâse ao ambiente da educação de infância, que se revela um meio, por excelência, para trocas musicais, quer entre crianças, quer entre crianças e adultos. Apesar 
deste carácter, aparentemente informal da música, a sua importância é extrema logo desde a primeira infância já que, e de acordo com Gordon (200ob), existem períodos críticos para a aprendizagem associados ao surgimento de conexões neurológicas e sinapses, que ocorrem antes do nascimento e durante a primeira infância. Neste sentido, se as oportunidades que a Natureza oferece às crianças não forem usadas durante estes períodos cruciais, acabam por se perder. Por este motivo Gordon (20oob, p.3) defende que "o nosso potencial para aprender música nunca é tão elevado como no momento em que se nasce, e que a partir daí diminui gradualmente".

A aptidão musical de uma criança é inata: tal como não existem crianças sem inteligência, também não existem crianças sem aptidão musical. A aptidão é afetada pela qualidade do meio em que se vive: "[d]ado que, para a maior parte dos recém-nascidos, o ambiente musical não é tão rico como deveria ser, é de esperar que o nível de aptidão musical com que as crianças nascem decresça" (GORDON, 20oob, p.i6). Esta ideia, de que a música não é um dom reservado apenas a um grupo de eleitos, é também defendida por François Delalande (1982) e por Patricia Campbell (1998) referenciados por Romanelli (2014, p.63) que afirmam, respetivamente, que "até aos dois anos de idade todas as crianças são igualmente talentosas, ou seja, todas têm enorme potencial para se desenvolver musicalmente" e que "não existe uma criança que seja a-musical". Assim, o facto de o nível mais elevado de aptidão musical se verificar no momento do nascimento e de esta aptidão depender da qualidade musical do meio, torna inestimável a importância de desde cedo se usufruir de um ambiente musical adequado. Contudo, Gordon enfatiza que a crucial importância da música na infância não significa que as crianças pequenas devam ser forçadas a aprender e a escutar música, já que "uma tal coerção seria mais prejudicial para o desenvolvimento musical [...] do que pouco ou nenhum contacto com a música" (GORDON, 2000a, p. 306). É através da brincadeira que a criança se relaciona com o mundo e é dessa forma que deve fazer música: brincando. O carácter lúdico da orientação para a música na primeira infância é, de igual modo, defendido por Agosti-Gherban e Rapp-Hess (1988, p. 23), que acreditam que se deve investir tempo com a aculturação musical, "habituando as crianças [...] a ouvir o que nos rodeia, a brincar com os sons”. Desta forma, e segundo as Orientações Curriculares para a Educação Pré-Escolar (LOPES DA SILVA, 2016), a abordagem à música deve dar continuidade às emoções e afetos vividos nas experiências quotidianas da criança, contribuindo para o seu prazer e bem-estar.

Neste sentido, a música tem, de facto, um papel importante no desenvolvimento da criança desde a primeira infância já que, tal como Rodrigues (1998, p. 40) menciona, estimular o pensamento musical é "possibilitar que a criança estabeleça com a música uma relação de compreensão, permitindo-lhe o acesso a uma experiência única de uma parte importante da sua cultura".

\section{O papel da família e do contexto educativo na aculturação musical das crianças}

As conceptualizações relativas à influência da música nas crianças e sua consequente importância na infância, não são unívocas, contrapondo-se, sobretudo, duas visões justificativas de uma aposta musical na infância: uma perspetiva que defende o valor intrínseco da música, declarando o seu valor inato como uma das linguagens humanas; e outra perspetiva que faz valer uma visão utilitária da música, como um meio de facilitação do desenvolvimento ou reforço de outras capacidades. 
Autores como Rodrigues (2003, p. 5I), apoiam uma conceptualização do valor inato da música, defendendo que "a experiência humana e o contacto com outras realidades proporcionado pela experiência musical são únicos, insubstituíveis e, portanto, suficientes para se autojustificarem"; da mesma forma, rejeitam argumentos relacionados com a conceptualização da música como ferramenta, considerando-os irrelevantes, tendo em conta a sua riqueza intrínseca. A mesma visão é partilhada por Romanelli (2014, p. 64): "[s]em negar as possibilidades interdisciplinares que a música apresenta, ela é antes de tudo uma forma de conhecimento que deve fazer parte do cotidiano das crianças com o objetivo de desenvolvimento musical”. Importa referir, ainda, a ideia de Campbell e Scott-Kassner (2018, p.5) que acreditam que "a música é a sua própria disciplina ao mesmo tempo que informa as crianças acerca do seu mundo, de forma interdisciplinar". Por outro lado, Sousa (2003) parece, de certo modo, defender o caracter utilitário da música, no sentido em que mais do que atribuir-lhe um valor inato e relevante, aparenta considera-la "uma ferramenta educacional, usada por educadores e professores" (SOUSA, 2003, p. 20). Embora não defenda o desenvolvimento de competências relacionadas com outras áreas, as palavras do autor vão ao encontro das de Schafer, por ele referido, de que a música não deverá ser o principal objetivo: "[o] objetivo da educação musical não será a música, mas a educação” (SOUSA, 2003, p.120).

A revisão de literatura mostra, de facto, divergências no modo de conceptualizar a música na infância, mas, independentemente da conceptualização defendida, é inequívoca a sua importância. O que tem vindo a acontecer é uma luta em defesa da valorização da música no sentido de mostrar a sua importância enquanto forma de arte $e$ de expressão/comunicação e como parte importante de cada cultura.

Partilhando uma ou outra visão, certa é a responsabilidade que os educadores de infância têm na aculturação musical das crianças, tendo por dever apostar numa pedagogia que a valorize, que possibilite a experimentação de diversos tipos e géneros de música e a vivência de inúmeros momentos onde esta seja a atriz principal, já que a música integra a cultura de todas as crianças e o principal objetivo da educação de infância deve ser, sempre, tal como defende Sousa (2003, p.18) "a formação como ser, como pessoa, o desenvolvimento equilibrado da sua personalidade". Do mesmo modo, Agosti-Gherban e Rapp-Hess (1988, p.i7) acreditam que "o mais importante é que as crianças aprendam desde a sua tenra infância a escutar, não para virem a ser músicos, mas sim para se desenvolverem harmoniosamente".

Sabendo-se que é durante a primeira infância que a criança apresenta maior disponibilidade biológica para a aprendizagem, percebe-se a importância de um investimento na aculturação musical desde cedo, no sentido de proporcionar à criança a possibilidade de viver experiências musicais diversificadas, que se relacionem com a audição (e audiação), a imitação, a experimentação e a criação musical. Isto porque se sabe não ser possível colmatar as falhas de aprendizagem causadas pela perda de oportunidades que uma criança sofre no período chave de estabelecimento dos fundamentos de aprendizagem, que é a primeira infância. De qualquer modo, importa perceber: antes da educação musical formal, é necessária a orientação para a música. E esta orientação tem (ou deve ter) lugar exatamente durante estes períodos críticos, que correspondem, grosso modo, à educação não obrigatória - Creche e Pré-Escolar. Trata-se de orientação para a música e não de Educação Musical, pelo que não devem ser impostas competências e conhecimentos às crianças tendo em conta os objetivos da Educação Musical. Espera-se, sobretudo, que as crianças sejam 
postas em contacto com a música e sejam encorajadas a absorvê-la, e isso só é possível se os adultos tiverem em consideração os seus interesses. Trata-se, nestes primeiros anos, de aprender brincando!

Sobre o papel dos pais e educadores de infância, interessa referir a importância do facto de esta aculturação musical dever ser feita de uma forma natural, incluída no quotidiano da casa e nas atividades da Creche/Jardim de Infância, ressalvando-se, assim, o seu carácter de orientação para a música e não de Educação Musical. Agosti-Gherban e RappHess (1988, p.15) defendem que o papel dos pais e dos educadores "é o de ajudar a criança a 'abrir-se', isto é, despertá-la para o mundo que a rodeia”. Deste modo, se os adultos dedicarem o tempo necessário ao desenvolvimento musical das crianças desde o nascimento, "elas virão a sentir-se mais à vontade com todos os tipos de música numa idade mais precoce e desenvolverão atitudes positivas em relação à música que persistirão ao longo da vida" (GORDON, 20oob, p.7). O papel do adulto na orientação musical da criança é uma questão abordada também por Hohmann e Weikart na sua obra Educar a Criança (1997), onde os autores defendem que é sua função proporcionar o máximo de experiências musicais possíveis, no sentido de fazer florescer as suas capacidades musicais. Percebendo-se a necessidade de apoio das crianças para descodificar a música, percebe-se o valor que um investimento concreto na aculturação musical detém, do mesmo modo que se percebe a importância atribuída à família e aos contextos educativos, no sentido de orientar as crianças, permitindo-lhes o desenvolvimento de competências, de modo a que venham a construir bases para compreender e comunicar através da música, tendo a competência de assumi-la como uma das muitas linguagens humanas.

Torna-se ainda pertinente referir Sousa (2003, p.120-122), no sentido de afirmar que o principal objetivo deve ser o constante estímulo da criança para "experimentar novas situações sonoras e usufruir desse prazer”. A importância das famílias e dos contextos educativos na aculturação musical das crianças prende-se, assim, com a assunção do seu papel enquanto orientadores, enquanto motivadores permanentes e estimuladores das experimentações e descobertas das suas crianças, já que, tal como acredita Gordon (20oob), não se vive sem música e, por isso, é-lhes vantajoso que a compreendam.

\section{A implementação do projeto: Levar a música à Creche: a importância de vivências musicais}

O Projeto Levar a música à Creche: a importância de vivências musicais foi desenvolvido numa Instituição Particular de Solidariedade Social, localizada no centro da cidade de Guimarães, Portugal. O grupo de crianças que participou era composto por 20 crianças (8 meninos e 12 meninas), entre os dois e os três anos de idade. Desde o início do percurso de estágio curricular que o grupo se mostrou particularmente interessado pela área da música e foi este mesmo interesse que esteve na base do planeamento de todo o Projeto de Intervenção Pedagógica.

Numa tentativa de dar continuidade ao trabalho desenvolvido pela equipa educativa e pela instituição de forma geral, a abordagem pedagógica adotada na prática pedagógica foi a Metodologia High/Scope. Uma metodologia que prima pela valorização da individualidade de cada criança, ser único e pensante, e da aprendizagem ativa, como meio privilegiado de aprendizagem.

A metodologia de investigação utilizada foi uma aproximação à Metodologia de Investigação - Ação, que auxiliou a perceção dos resultados do projeto nas suas diversas fases, assim como serviu de metodologia auxiliar na resolução de problemas, uma vez que 
permitiu, através do ciclo Observação - Ação - Reflexão, melhorar a cada dia a compreensão do contexto educativo e dos seus intervenientes. Os instrumentos de recolha de dados, que objetivaram não só a construção e desenvolvimento do Projeto como também toda a prática pedagógica, foram a observação e reflexão, suportadas por um conjunto elaborado de notas de campo e registos fotográficos. Para terminar as referências aos instrumentos de recolha de dados utilizados, importa mencionar, ainda, a Escala de Envolvimento da Criança, incluída no documento disponibilizado pelo Ministério da Educação - Manual DQP Desenvolvendo a Qualidade em Parceria (BERTRAM; PASCAL, 2009), utilizada na avaliação de todas as atividades propostas ao grupo e que serviu, de acordo com os seus indicadores e níveis de atividade, para perceber de que forma as crianças se envolveram nas tarefas, dando, dessa forma, uma ideia do sucesso ou insucesso da sua adequabilidade e realização. De acordo com Perry (2010), uma planificação cuidada das experiências musicais para crianças pode fazer a diferença no modo como estas aprendem a apreciar a música. Neste sentido, todas as propostas apresentadas ao grupo tiveram por base uma planificação cuidadosa, baseada na interligação entre experiências chave e indicadores chave de desenvolvimento (instrumentos disponibilizados pela Fundação High/Scope), com o principal objetivo de oferecer às crianças oportunidades de aprendizagem ativa e usufruto musical, através de atividades diversificadas e estimuladoras. As propostas apresentadas foram cuidadosamente refletidas e avaliadas, no sentido de serem cada vez mais adequadas aos interesses e necessidades do grupo. Deste modo, são explicitadas, a seguir, três das propostas que compuseram o Projeto Levar a música à Creche: a importância de vivências musicais.

\section{I Vamos conhecer o Bernardino e muitos instrumentos musicais}

Uma das grandes potencialidades da leitura de histórias é a criação de relações afetivas com as crianças. Da mesma opinião são Hohmann e Weikart (1997, p.547) que referem que:

através da leitura de histórias às crianças, pelos pais, outros membros da família ou quaisquer adultos significativos, cria-se um laço emocional e pessoal muito forte, de forma que as crianças passam a associar a satisfação intrínseca a uma relação humana muito significativa com as histórias e a leitura.

Este foi o principal motivo para a escolha desta primeira atividade: iniciar o projeto com uma proposta que permitisse, desde logo, o contacto direto e natural com as crianças. Mas, a leitura da obra Bernardino, de Manuela Bacelar (2016), e a exploração da história foram apenas o início da atividade: aproveitando o facto de o Leão Bernardino ter ficado a perceber, ao longo do tempo da história, que gostava de música e de tocar flauta e que a música assume possibilidades de união entre pessoas; o objetivo foi também proporcionar às crianças a exploração livre de diversos instrumentos musicais, muitos dos quais estas crianças nunca tinham visto, permitindo que executassem individualmente e em grupo, que trocassem impressões e comentários e se divertissem durante o momento de exploração. De igual modo, a atividade materializou-se como uma oportunidade de contacto com uma obra de literatura infantil que, associada à música, promoveu a aprendizagem ativa e o usufruto musical. Sendo assim, era objetivo que as crianças fossem capazes de: participar no diálogo 
de análise da história, explorar diferentes instrumentos musicais demonstrando iniciativa durante a mesma, e explorar tons vocais, cantando e tocando em simultâneo.

A escolha dos instrumentos musicais a explorar regeu-se por dois critérios: instrumentos cuja quantidade fosse considerável e instrumentos de manuseamento fácil. Desta forma, importa agora apresentar a sequência de momentos vivida com o grupo: (i) exploração da capa, contracapa, título e abas iniciais e finais da obra; (ii)leitura da história; (iii) diálogo sobre a flauta e exploração da flauta enquanto instrumento musical; (iv) diálogo sobre outros instrumentos conhecidos do grupo; (v) exploração livre de outros instrumentos (castanholas, maracas, tamborins e pandeiretas); (vi) canção de temas musicais conhecidos do grupo, com o acompanhamento dos instrumentos.

O balanço geral da atividade foi extremamente positivo. A obra escolhida para iniciar a proposta era curta e foi apresentada ao grupo de forma interativa, intercalando a leitura da história com questões e tentativas de previsão do que aconteceria a seguir. As distrações durante a leitura foram em número muito reduzido (apenas duas crianças apresentaram alguma distração) e de curta duração. Neste sentido, o decorrer do primeiro momento foi extremamente satisfatório, já que a atenção das crianças se encontrava virada para a atividade. Nem mesmo quando alguma criança apresentava uma distração pontual, o grupo se distraía da leitura, mostrando profunda concentração e persistência. Tendo em conta que era sobretudo uma atividade de observação e escuta, a energia mental que as crianças depositaram na atividade foi visível através das suas expressões faciais e postura, que revelaram atenção e concentração. Importa ainda mencionar que sempre que estimuladas, com perguntas ou previsões, as crianças responderam com rapidez. "As crianças que estão envolvidas estão atentas e reagem com rapidez a estímulos" (BERTRAM; PASCAL, 2009, p.130). A satisfação do grupo foi visível, mais uma vez, quer através da sua linguagem corporal, quer da sua linguagem verbal.

Terminada a leitura, foi tempo de apresentar em tamanho real e ao vivo o instrumento musical referido na história: a flauta de bisel. Foi interessante perceber que praticamente todas as crianças desconheciam o instrumento e ficaram surpreendidas quando o ouviram - muito provavelmente pela primeira vez. A exploração individual das flautas também se revelou bastante positiva. Todas as crianças quiseram experimentar e exploraram-na durante bastante tempo. Mais uma vez, as expressões faciais e a postura revelaram que o grupo estava envolvido e motivado. A persistência e a concentração são pontos importantes a referir, sendo que também neste momento as crianças continuaram a apresentar-se empenhadas na tarefa. O tempo de reação revelou-se um indicador importante, sendo que depois de apresentada a flauta e distribuídas várias flautas pelas crianças, não foi necessário qualquer tipo de incitação ou apelo, todos experimentaram de livre vontade e durante cerca de quatro minutos. Também a linguagem verbal se mostrou um indicador do envolvimento do grupo, sendo que para além dos risos de satisfação, as crianças chamavam os adultos da equipa educativa, para que os vissem e ouvissem tocar.

O terceiro momento da proposta foi aquele que se revelou mais satisfatório, no que diz respeito aos efeitos pretendidos no grupo, e prendeu-se com o diálogo acerca dos instrumentos conhecidos do grupo e exploração livre de diferentes instrumentos disponibilizados. Como ainda havia algumas crianças na sala com pouca independência, não era expectável que fossem todos tão autónomos e participantes, num momento cujo objetivo era que explorassem sozinhos, escolhessem instrumentos, alterassem as suas escolhas, se necessário, e usufruíssem da oportunidade de criar música. Foi muito satisfatório perceber 
que todos se envolveram no processo de exploração e criação, demonstrando emoções e participando ativamente. Neste contexto, mais uma vez, tendo em conta os indicadores propostos no Manual DQP, é possível comprovar o envolvimento das crianças: demonstraram muita energia, tocando ruidosamente os seus instrumentos; persistência, tocando mais e mais até que lhes fosse pedido para fazerem silêncio, transparecendo satisfação, sobretudo verbalmente, tecendo comentários, rindo e chamando a atenção dos adultos para o seu trabalho.

A parte final da atividade, onde se pretendia que as crianças cantassem as canções que já conheciam e que costumavam cantar em diversos momentos e acompanhassem o canto com os seus instrumentos, foi também reveladora: apesar de não ter sido bemsucedida, já que a maioria das crianças não foi capaz de tocar e cantar ao mesmo tempo, no entanto foi evidenciadora do interesse do grupo na exploração de instrumentos. A maior parte do grupo não cantou, apenas acompanhou, tocando o seu instrumento alegre e intensamente, o que se deveu ao facto de se encontrarem imersos na exploração e entusiasmados com a ideia de terem instrumentos suficientes para todos, podendo todos, em conjunto, explorar e criar música, cada um com o seu instrumento.

\subsection{Os sons naturais também são música}

A música é muito mais do que o conjunto de canções que as crianças estão habituadas a ouvir na rádio e que aprenderam a cantar, ou mesmo o conjunto de sons produzidos pelos instrumentos que conhecem, ouvem e exploram. É importante que percebam que a sua voz é um instrumento, assim como a voz (timbre) dos animais; que podem fazer música com o próprio corpo; e que, da mesma forma, os sons da Natureza também podem ser música.

O objetivo desta proposta era que percebessem que, tal como se faz música com instrumentos e através do canto, também os sons naturais podem ser utilizados para fazer música. Com o decorrer da atividade era espectável que as crianças se mostrassem capazes de participar ativamente na comunicação, identificando e explorando as imagens fornecidas e explorando tons vocais através da imitação dos sons correspondentes às imagens apresentadas. Representava, também, um objetivo, a exigência de concentração e atenção, assim como imaginação e criatividade. Deste modo, tal como todas as atividades do Projeto, também esta foi pensada no sentido de permitir usufruto musical e promover a aprendizagem ativa através da música.

A atividade realizou-se em pequenos grupos, no espaço exterior, e seguiu a seguinte sequência: (i) diálogo com o pequeno grupo sobre a música e sobre os sons naturais enquanto música; (ii) explicação do sentido do jogo: a cada imagem apresentada as crianças deverão associar o respetivo som, imitando-o; (iii) apresentação de imagens e exploração dos respetivos sons, com recurso a uma apresentação PowerPoint; (iv) apresentação do som real correspondente a cada imagem apresentada (depois da exploração/imitação).

A cada grupo foi apresentada a seguinte sequência de imagens: chuva, cão, vento, galinha, bebé a chorar, ovelha, ondas do mar, gato, vaca, trovão, porco, abelha, palmas, pássaros e bebé a rir. Ao ver as imagens, as crianças identificavam-nas e eram incentivadas a pensar sobre o som que lhes correspondia. Depois de pensarem sobre ele e o tentarem reproduzir, ouviam o som real na apresentação. A criação de uma apresentação em formato PowerPoint permitiu desencadear a atividade de forma mais divertida, já que depois de 
imitarem e explorarem tons vocais, tinham a possibilidade de ouvir o som real e adequar as suas imitações.

De uma maneira geral, as crianças responderam de forma muito positiva no que diz respeito à correspondência imagem-som e na reprodução/imitação dos sons. As dificuldades foram generalizadas aquando da apresentação da imagem do vento, das ondas do mar e do trovão. Dificuldades que foram colmatadas, exemplificando, reproduzindo o som da apresentação mais do que uma vez e ajudando o grupo na imitação em simultâneo. Ainda assim, o envolvimento e entusiasmo das crianças foi facilmente verificável através das suas expressões faciais e postura, que revelaram satisfação. A concentração e esforço investido na atividade expressaram-se, sobretudo, no seu tempo de reação, sempre muito rápido, aquando de alguma questão. Mostraram-se interessados, fazendo, por vezes, outros comentários sobre as imagens que viam, para além do aspeto sonoro. Mesmo aquelas crianças que se mostraram com mais dificuldade em imaginar e produzir o som, facilmente o reproduziam quando se tratava de o fazer em conjunto com os colegas.

O momento de audição do som real foi um momento que se pautou, também ele, por um grande entusiasmo dos grupos, que ficavam sempre muito atentos. No final de cada imagem, quando se lhes perguntava: Vamos ver outra?, a resposta vinha sempre por entre muitos sorrisos, palmas e remexeres na cadeira, um Siiiim, sempre muito entusiasmante.

\subsection{Somos uma orquestra}

Esta proposta surgiu no sentido de ir ao encontro do interesse do grupo, uma vez que o jogo a ela associado havia já sido proposto numa atividade anterior. O comummente chamado, pelas crianças, jogo do maestro (Somos uma Orquestra I), consistiu numa espécie de recriação de uma orquestra, onde cada criança se colocava no papel de músico, seguindo as ordens do maestro. Antes da realização do jogo em si, o grupo visualizou um vídeo relativo à atuação de uma orquestra e dialogou acerca do mesmo, com especial ênfase no papel do maestro e suas funções.

$\mathrm{Na}$ proposta Somos uma Orquestra (I), o jogo foi realizado com recurso aos instrumentos convencionais cedidos pela instituição; desta vez, cada criança jogou utilizando uma maraca não convencional que havia anteriormente construído. Deste modo, esta proposta surgiu com o principal objetivo de proporcionar ao grupo um momento para escutar música e para observar, experimentar, tocar e criar. A estrutura de momentos obedeceu à seguinte ordem: (i) visualização de um vídeo referente à atuação de uma orquestra; (ii)diálogo com o grupo acerca das funções do maestro; (ii) exploração livre das maracas; (iii) recapitulação das regras do jogo: braços esticados na horizontal com as mãos abertas, todas as crianças tocam, braços esticados na horizontal com as mãos fechadas, todos fazem silêncio; (iv) realização do jogo segundo as regras combinadas aquando da realização da proposta Somos uma Orquestra (I); (v) apresentação de novas regras: braços esticados para cima com as mãos abertas, as crianças tocam rápido, braços esticados para baixo com as mãos abertas, as crianças tocam lentamente; (vi) continuação do jogo de acordo com as regras apresentadas.

Â semelhança do que havia acontecido na primeira realização desta dinâmica, o grupo mostrou-se sempre muito interessado na visualização do vídeo e muito entusiasmado na exploração dos instrumentos e realização do jogo. Importa dizer que o vídeo apresentado ao grupo foi uma aposta arriscada, já que tinha uma duração de aproximadamente seis 
minutos e 30 segundos. Ainda assim, apesar de ser um vídeo de música erudita - Tom and Jerry, pela John Wilson Orchestra - e da sua duração relativamente longa, o grupo mostrouse muito recetivo e interessado, entusiasmando-se mais ainda nas partes mais aceleradas do vídeo.

O entusiasmo do grupo revelou-se desde cedo, já que sabiam que iriam realizar o jogo do maestro. Quando questionadas acerca das regras, com recurso aos movimentos associados a cada uma, as crianças rapidamente responderam dizendo o que deveriam fazer. $O$ facto de ainda se lembrarem das regras, mesmo passado todo o tempo que separou as duas propostas, demonstra que o grupo se encontrava, de facto, motivado. Aquando da distribuição das respetivas maracas a cada criança, mesmo antes de iniciar o jogo, foi visível o interesse das crianças, que começaram de imediato a explorar o instrumento que haviam construído e a tocar alegremente.

Apesar de anteriormente a dinâmica ter sido realizada com instrumentos convencionais e, desta vez, com um instrumento não convencional com o toque pessoal de cada criança, a exploração desse mesmo instrumento havia já sido feita. Contudo, todas as crianças demonstraram entusiasmo na (re)exploração, divertindo-se e envolvendo-se na dinâmica, explorando e usufruindo do momento musical. Tendo em conta os indicadores da Escala de Envolvimento da Criança, incluída no Manual DQP, foi percetível o usufruto musical, quer através da sua linguagem verbal, que incluiu muitos risos de satisfação, quer através da sua postura e expressões faciais. Mais uma vez, respeitaram a comunicação nãoverbal estabelecida em forma de regras de jogo, mobilizando as suas capacidades cognitivas de forma a dar uma resposta rápida e adequada aos estímulos. A persistência foi, ainda, um indicador a ter em consideração, tendo em conta que todo o grupo investiu o seu tempo na atividade, mostrando-se atento e interessado em continuar, não se deixando distrair.

\section{Considerações finais}

Os objetivos que sustentaram o Projeto foram cumpridos com sucesso, com muitos indicadores de entusiasmo e interesse nos momentos de experimentação e com comprovado usufruto dos momentos musicais. Para além de terem experienciado e partilhado diversas vivências musicais, facto que, por si só, constituía um dos principais objetivos do trabalho, as crianças mostraram-se capazes de usufruir dos diversos momentos, apresentando empenho, envolvimento e dedicação, para além de um enorme entusiasmo e uma certa ânsia em viver momentos lúdicos, proporcionados por esta intervenção pedagógica, ou as diferentes explorações de instrumentos musicais. Parece-me ainda importante referir que a aprendizagem ativa foi um objetivo sempre presente quer na planificação das propostas, quer ao longo da sua execução, daí que estas tenham adotado um carácter lúdico, muitas vezes em forma de jogo, já que é brincando que as crianças aprendem.

O Projeto revelou-se ainda um importante fator de desenvolvimento da autonomia $e$ do sentido de convivência em grupo, já que muitas das explorações permitiram a escolha livre e a mudança dessa escolha, potenciando a autonomia (pouco visível em algumas crianças do grupo). Do mesmo modo, as explorações realizadas em grande grupo possibilitaram a troca de impressões e comentários durante o decorrer das atividades e promoveram a partilha, quer de materiais, quer de experiências, estimulando o sentido de vivência em grupo e o sentimento de pertença. Por todos estes motivos, é possível comprovar o sucesso da implementação do Projeto Levar a música à Creche: a importância de 
vivências musicais. Contudo, é ainda importante expor que o processo não contribuiu com dados concretos para a clarificação do seu último objetivo (compreender o potencial da música na infância). Ainda assim, a análise de referenciais teóricos, associada à reflexão das reações das crianças às diferentes propostas, permitem aferir que a aposta na aculturação musical desde tenra idade representa um investimento na educação holística da criança e contribui em grande medida para a criação de atitudes positivas perante a música. Neste sentido, é possível afirmar-se que a música tem um enorme potencial, que deve ser trabalhado com as crianças desde a primeira infância, no sentido de criar oportunidades para que estabeleçam relações de afetividade com a música, oferecendo-lhes a possibilidade de contactar com uma parte importante da sua cultura.

No caso específico dos contextos de educação de infância, as explorações musicais encerram-se, não poucas vezes, no seu valor instrumental, não lhes sendo dedicado nenhum momento específico da rotina diária ou semanal. Por isso, e apesar de se notar, atualmente, um maior investimento das instituições na área, estamos ainda longe de uma aposta séria na aculturação musical das nossas crianças. Neste sentido, um dos maiores desafios do ensino da música no século XXI passa, exatamente, pela mudança de mentalidades, ideias préconcebidas e formas de atuação que, propositadamente ou não, relegam a música para segundo plano.

A capacidade intrínseca de todas as crianças para absorver todo o tipo de estímulos é razão mais do que suficiente para justificar uma abordagem musical desde o nascimento, com vista ao desenvolvimento holístico e à formação pessoal e social equilibrada da criança, que significa, intransigentemente, um contacto apropriado com as diversas formas de arte, expressão e comunicação, sem que umas sejam valorizadas em detrimento de outras, já que, como nos diz Gordon (200oa, p.6) "a música [...] como as outras artes, é tão básica como a linguagem para a existência e o desenvolvimento humano". Quando todo o universo da educação de infância souber que é mesmo antes do nascimento que começa a aculturação musical das crianças e quando todos os pais e educadores de infância perceberem que não precisam de ser professores de Educação Musical para contribuírem para essa mesma aculturação, a educação, no geral, dará um gigantesco passo rumo ao desenvolvimento holístico das crianças.

\section{Referências}

AGOSTI-GHERBAN, Cristina; RAPP-HESS, Cristina. El niño, el mundo sonoro y la música. San Eloy: Editorial Marfil, 1988. ing p.

BACELAR, Manuela. Bernardino. 3ª ed. Porto: Edições Afrontamento, 2016. 28 p.

BERTRAM, Tony; PASCAL, Cristine. Manual DQP: Desenvolvendo a Qualidade em Parcerias. Lisboa: Ministério da Educação: Direcção-Geral de Inovação e de Desenvolvimento Curricular, 2009. $200 \mathrm{p}$.

CAMPBELL, Patricia Shehan; SCOTT-KASSNER, Carol. Music in childhood: from preschool through the elementary grades. $4^{\underline{a}}$ ed. Boston MA: Cengage Press, 2018. 398 p. 
GORDON, Edwin. Teoria da aprendizagem musical - competências, conteúdos e padrões. Lisboa: Fundação Calouste Gulbenkian., 2000a. 518 p.

GORDON, Edwin. Teoria da Aprendizagem musical para recém-nascidos e crianças em idade pré-escolar. Lisboa: Fundação Calouste Gulbenkian, 200ob. 174 p.

HOHMANN, Mary; WEIKART, David. Educar a Criança. Lisboa: Fundação Calouste Gulbenkian, 1997. 824 p.

LECANUET, Jean Pierre; SCHAAL, Benoist. Fetal sensory competencies. European Journal of Obstetrics \& Gynecology and Reproductive Biology, v.68, n. I-2, p. I-23, 1996. doi: 10.1016/0301-2115(96)02509-2

LOPES DA SILVA, Isabel (Coord.). Orientações Curriculares para a Educação PréEscolar. Lisboa: Ministério da Educação, 20ı6. ııo p.

MOOG, Helmuit. The Development of Musical Experience in Children of Pre-School Age. Psychology of Music, v. 4, n. 2, p. 38-45, 1976. doi:10.1177/030573567642005

PARNCUTT, Richard. Prenatal experience and the origins of music. In: BLUM, T. (Ed.) . Prenatal Perception. Berlin: Leonardo Publ, 1993. p. 253-277.

PERRY, Craig. A música na educação de infância. In: SPODEK, B. (Org.). Manual de Investigação em Educação de Infância. Lisboa: Fundação Calouste Gulbenkian, 2oro. p. 46I492.

RODRIGUES, Helena. Música para os pequeninos - elementos da perspectiva de Edwin Gordon. Cadernos de Educação de Infância, nº 48, p. 39-4I, 1998.

RODRIGUES, Helena. Bebé Babá - da musicalidade dos afectos à música com bebés. Porto: Campo das Letras, 2003. 93 p.

ROMANELLI, Guilherme . Antes de falar as crianças cantam! Considerações sobre o ensino de música na educação infantil. Teoria e Prática da Educação, v.17, no 3, p. 6I-71, 2014.

SOUSA, Alberto. Educação pela arte e artes na educação - música e artes plásticas. Lisboa: Instituto Piaget, 2003. 396 p. 